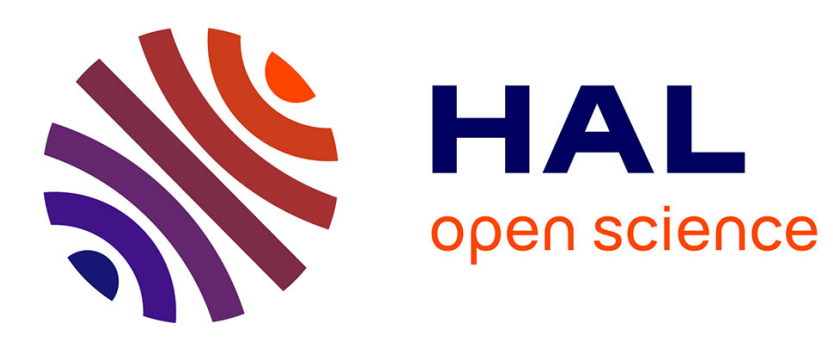

\title{
Surface properties of low specific surface powders using inverse gas chromatography
}

S Comte, Rachel Calvet, John A. Dodds, H Balard

\section{To cite this version:}

S Comte, Rachel Calvet, John A. Dodds, H Balard. Surface properties of low specific surface powders using inverse gas chromatography. Powder Technology, 2005, 157 (1-3), pp.39-47. 10.1016/j.powtec.2005.05.029 . hal-01680770

\section{HAL Id: hal-01680770 https://hal.science/hal-01680770}

Submitted on 20 Nov 2018

HAL is a multi-disciplinary open access archive for the deposit and dissemination of scientific research documents, whether they are published or not. The documents may come from teaching and research institutions in France or abroad, or from public or private research centers.
L'archive ouverte pluridisciplinaire HAL, est destinée au dépôt et à la diffusion de documents scientifiques de niveau recherche, publiés ou non, émanant des établissements d'enseignement et de recherche français ou étrangers, des laboratoires publics ou privés. 


\title{
Surface properties of low specific surface powders using inverse gas chromatography
}

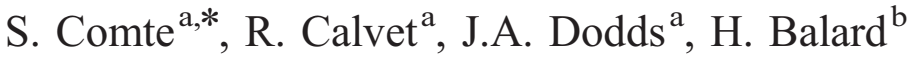 \\ ${ }^{a}$ Ecole des Mines d'Albi-Carmaux, Route de Teillet, 81013 Albi CT Cedex 09, France \\ ${ }^{\mathrm{b}}$ Institut de Chimie des Surfaces et Interfaces, 15 rue Starcky, 68057 Mulhouse, France
}

\begin{abstract}
Inverse Gas Chromatography (IGC) is used to study the influence of relative humidity and chemical treatment with sulfochromic acid on the surface properties of glass beads. The humidity of the carrier gas to the chromatograph is controlled by means of a specially designed humidity generator to allow investigation of the surface of powders attributed to the progressive coverage by water molecules. The solid under test is glass beads with a very a low specific surface and the properties studied are the specific surface, thermodynamic parameters and the proportions of silanol and siloxane groups on the surface.
\end{abstract}

Keywords: Adsorption; Relative humidity; Surface acid-base characteristics; Inverse gas chromatography; Glass beads

\section{Introduction}

Many studies have been made of the influence of water adsorption on the surface properties of solids, for example pharmaceutical excipients such as sugars [1,2], food products like wheat and soy flour [3,4], cotton [5], or mineral solids [6]. This list is far from exhaustive.

Two indirect techniques are usually used for the surface energy of solids: vapour adsorption measurements using probe vapours, and wetting measurements using liquid probes [7]. The measurement of contact angles suffers from very poor reproducibility, whereas vapour adsorption techniques give good results.

Amongst the vapour adsorption techniques Inverse Gas Chromatography (IGC) is getting increasing attention as it offers several advantages such as the possibility of using a variety of probes and a large range of temperatures. The term "inverse gas chromatography" was introduced to denote that the interest is in the stationary phase in the column which may be a powder, a filler, a polymer material.

\footnotetext{
* Corresponding author.

E-mail address: calvet@enstimac.fr (S. Comte).
}

Contrary to conventional Gas Chromatography (GC) where the stationary phase serves to separate and identify the various gaseous components, IGC uses specific solute probes to determine interactions between the solutes and the solid column packing material under investigation [8]. There are two ways to perform IGC: infinite dilution (ID) [9] or finite solute concentration (CF) [10]. In the first mode, a very small amount of probe vapour, at the limit of detection of the flame ionisation detector (FID) is injected in the column and its retention volume determined. Under these conditions, Henry's law can be applied and the proportion of adsorbed probe, and therefore the retention volume, is independent of the probe concentration. In this case the injected probe molecules will explore the entire surface of the column packing and retention times will mainly reflect interactions with the strongly active sites on the solid surface examined. In finite solute concentration (CF) a liquid probe is injected instead of vapour which leads to the formation of monolayer of probe on the solid surface. In this case the finite solute concentration allows the determination of desorption isotherms and is a suitable method for evaluating the heterogeneity of the surface energy of powders. 
Previous studies [11-14] have been made on silicas and glasses in infinite dilution mode to study the influence of chemical grafting on the surface properties. The conclusions of this work underline the importance of the silanol groups on the solid surface. Here, we propose to study the influence of the relative humidity $p / p^{0}$ by IGC-ID on glass beads. The interest of these solids is their very low specific areas, less than $0.5 \mathrm{~m}^{2} / \mathrm{g}$, the objective being to test the limits of the IGC depending on the particle size. We determine the free energies, enthalpies and entropies of adsorption of apolar probes under different levels of humidity. Acid-base probes were also used to measure the acid-base characteristics of the solid surface. Secondly, we analyse the effect of a sulfochromic acid treatment on the surface properties of these glass beads.

\section{Theory}

Even though many publications have presented the theory of inverse gas chromatography at infinite dilution, it seems useful, to clarify the discussion and the interpretation of the results, to give a short description of the technique.

\subsection{Principles}

Inverse gas chromatography consists in measuring the chromatographic retention times of probes of known properties passing through a chromatography column packed with the solid material under test. The retention time of these probes, a function of the retention volumes, is related to the affinity of the probes for the solid surface. The retention volume $V_{\mathrm{N}}$ is readily calculated from the retention time by the following equation:

$V_{\mathrm{N}}=\left(t_{R}-t_{O}\right) \times D_{\mathrm{c}}$

where: $D$ is the corrected flow rate of the carrier gas, $t_{\mathrm{R}}$ and $t_{\mathrm{O}}$ are the retention times of the probe and methane, respectively.

The specific retention volume is usually used to compare results of different columns and temperatures. This volume corresponds to the retention volume normalised to a temperature of $273 \mathrm{~K}$ and to $1 \mathrm{~g}$ of powder.

$V_{\mathrm{g}}=\frac{273.5 \times V_{\mathrm{N}}}{T \times m}$

where $m$ is the amount of powder in the column and $T$ the measurement temperature.

The specific retention volume is related to the variation of the free energy of adsorption $\Delta G_{\text {ads }}$ in the following way:

$\Delta G_{\mathrm{ads}}=-\left(R \times T \times \ln V_{\mathrm{g}}\right)+C$

Here $C$ is a constant that depends on the choice of a reference state of the adsorbed probe and also on the total area of the solid accessible to the probe. Analyses made at different temperatures and the variation of $\Delta G_{\text {ads }}$ with the temperature, allow the determination of the enthalpy of adsorption:

$\Delta H_{\mathrm{ads}}=-R \frac{\partial \ln V_{\mathrm{g}}}{\partial\left(\frac{1}{T}\right)}$

The entropy of adsorption may be related to the enthalpy and the free energy of adsorption by the following equation:

$\Delta S_{\mathrm{ads}}=\frac{\left(\Delta H_{\mathrm{ads}}-\Delta G_{\mathrm{ads}}\right)}{T}$.

\subsection{The dispersive component of the surface energy}

Generally, the $\Delta G_{\text {ads }}$ takes into account two kinds of interactions: dispersive interactions (London forces) and acid base interactions (hydrogen bonding among others):

$\Delta G_{\mathrm{ads}}=\Delta G_{\mathrm{ads}}^{\mathrm{d}}+\Delta G_{\mathrm{ads}}^{\mathrm{sp}}$

The injection of alkanes allows determination of the dispersive component $\Delta G_{\text {ads }}$ d since these molecules can only interact by dispersive interactions. As the $\Delta G_{\text {ads }}$ varies linearly with the number of carbon of the $n$-alkane, it is possible to determine the incremental value $\Delta G_{\mathrm{ads}}^{\mathrm{CH}_{2}}$ which does not depend on the arbitrary choice of the standard reference state of the adsorbed alkane:

$\Delta G_{\mathrm{ads}}^{C H_{2}}=-R T \ln \left(\frac{V_{n+1}}{V_{n}}\right)$

Here $V_{n}$ and $V_{n+1}$ are the net retention volumes, respectively, of the alkanes with $n$ and $n+1$ atoms of carbon.

The free energy of adsorption can be related to the work of adhesion $W_{\mathrm{a}}$ between the probe and the solid surface:

$\Delta G_{\mathrm{ads}}=-N a W_{\mathrm{a}}$

where $N$ is Avogadro's number and $a$ the surface area of an adsorbed probe molecule.

When alkane probes are used, the dispersive interactions are dominant in the work of adhesion which can be related to $\gamma_{\mathrm{s}}^{\mathrm{d}}$ and $\gamma_{1}^{\mathrm{d}}$, the dispersive components of the solid and of the injected probe, respectively [15]:

$W_{\mathrm{a}}=-\frac{\Delta G_{\mathrm{ads}}^{\mathrm{CH}_{2}}}{N a}=2 \sqrt{\gamma_{\mathrm{s}}^{\mathrm{d}} \gamma_{1}^{\mathrm{d}}}$

According to Doris and Gray, and by combining Eqs. (7) and (10), the dispersive component of the surface free energy can be calculated as follow:

$\gamma_{\mathrm{s}}^{\mathrm{d}}=\frac{\left(\Delta G_{\mathrm{ads}}^{\mathrm{CH}_{2}}\right)^{2}}{4 N^{2} a_{\mathrm{CH}_{2}}^{2} \gamma_{\mathrm{CH}_{2}}}$ 


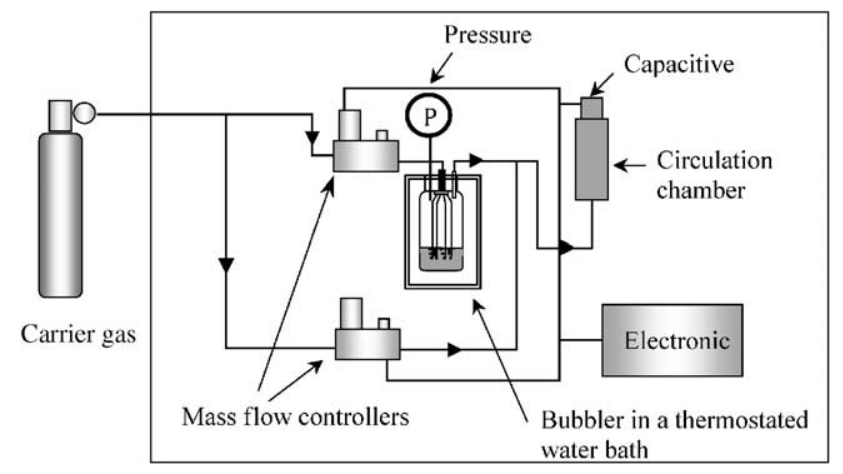

Fig. 1. Schematic diagram of the generator of humidity.

where $a_{\mathrm{CH} 2}$ is the area covered by one methylene group $\left(0.06 \mathrm{~nm}^{2}\right)$, and $\gamma_{\mathrm{CH} 2}$ is the surface energy of pure methylene group surface, i.e. polyethylene, $\gamma_{\mathrm{CH}_{2}}=35.6+$ $0.058(293-\mathrm{T})$, in $\mathrm{mJ} / \mathrm{m}^{2}$.

\subsection{Acid-base characteristics of the surface solid}

Polar molecules are used to assess the specific interactions $\Delta G_{\text {ads }}^{\text {sp }}$ that is to say all types of interactions except the London interactions. Among the specific interactions, acid-base are the most important. To estimate the contribution of the specific component $\Delta G_{\mathrm{ads}}^{\mathrm{sp}}$ to the free energy of adsorption of a polar probe, the contribution of dispersive interactions must be subtracted from the global free energy of the polar probe:

$\Delta G_{\mathrm{ads}}^{\mathrm{sp}}=\Delta G_{\mathrm{ads}}-\Delta G_{\mathrm{ads}}^{\mathrm{d}}$

The global free energy $\Delta G_{\text {ads }}$ of the polar probe is calculated from the specific retention volume $V_{\mathrm{g}}^{\text {spe }}$.

The $\Delta G_{\text {ads }}$ is estimated from the " $n$-alkanes reference line" obtained by plotting the variation of $\Delta G_{\text {ads }}$ of linear alkanes versus a given molecular descriptor such as the $\chi_{\mathrm{T}}$ determined using Wiener's indexes.

\section{Dry gas to the column}

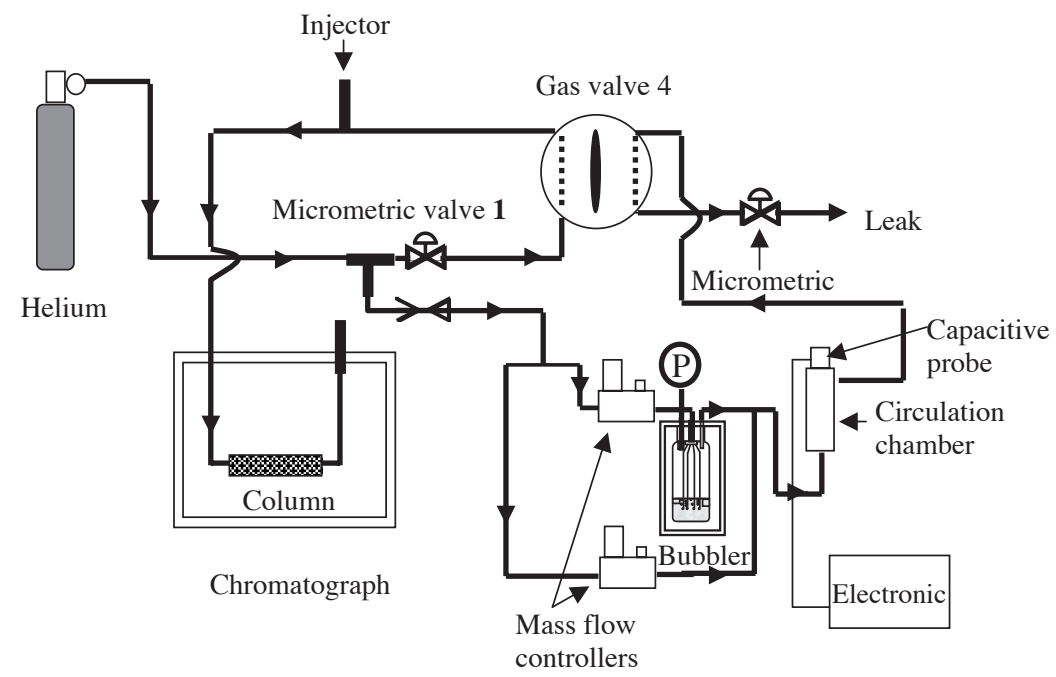

\section{Wet gas to the column}

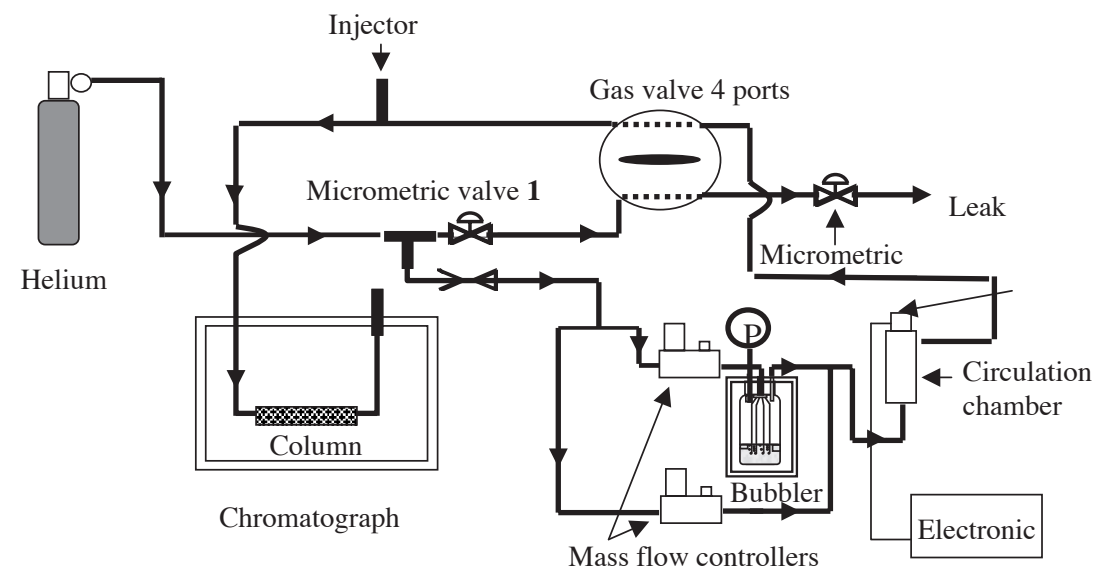

Fig. 2. Schematic diagrams of the assembly: humidity generator and chromatograph. 
To obtain acid-base indices of surfaces, the polar probes have to be classified by the acid (acceptor number AN) and base (donor number DN) characteristics. Two approaches are usually used: Drago and Gutmann semi-empirical scales. In this study, we used the Gutmann approach because the amphoteric character of the probes is considered. The relation between the acid and basic parameters of the solid surface is given by:

$$
-\Delta H_{\mathrm{ads}}^{\mathrm{sp}}=K_{\mathrm{a}} \times D N+K_{\mathrm{b}} \times A N
$$

Where $K_{\mathrm{a}}$ and $K_{\mathrm{b}}$ are indices reflecting the acidity and basicity of the surface.

According to the relation (12), a plot of $-\Delta H_{\mathrm{ads}}^{\mathrm{sp}} / \mathrm{AN}$ versus DN/AN leads to a straight line from which $K_{\mathrm{a}}$ is the slope and $K_{\mathrm{b}}$ the intercept.

\section{Apparatus}

\subsection{The humidity generator}

The humidity generator is presented in Fig. 1:

A system has been designed and built to provide a controlled humidity carrier gas. In this the input carrier gas
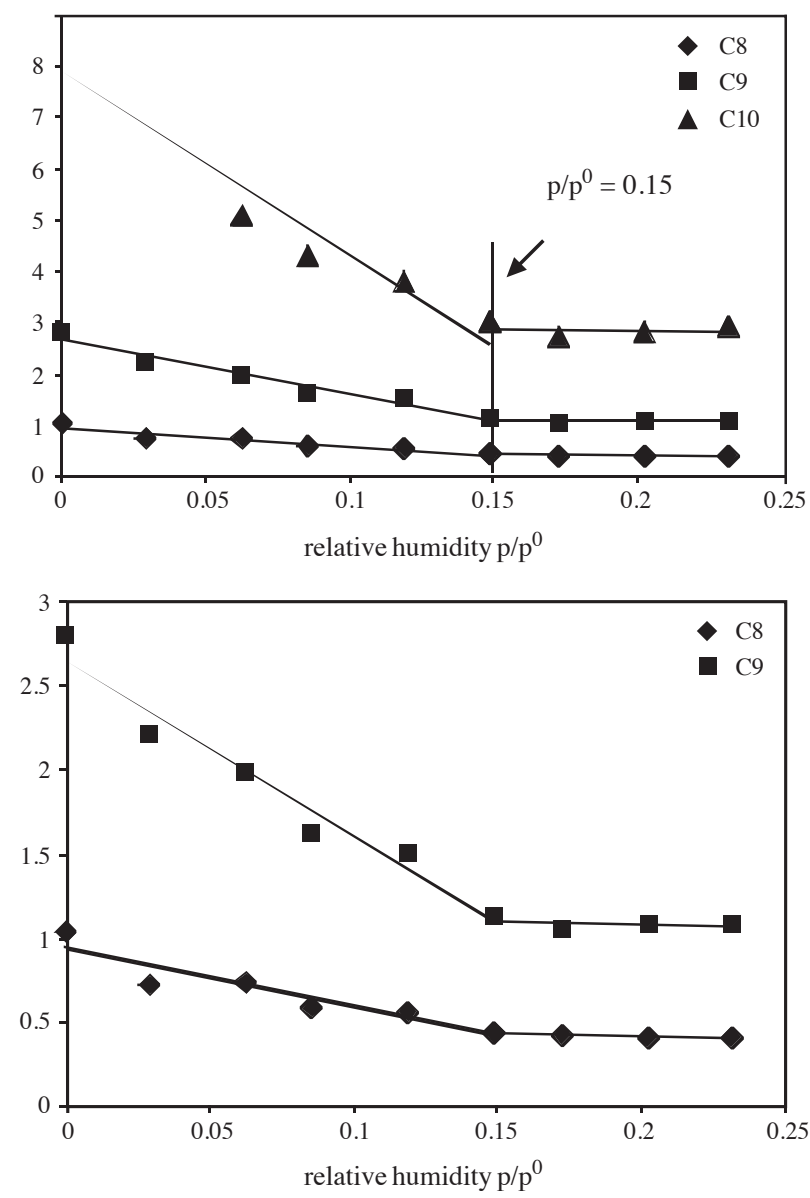

Fig.3. Evolution of specific retention volumes $V_{\mathrm{g}}$ of apolar molecules with the relative humidity $p / p^{0}$ on untreated glass beads $4590 \mathrm{NT}$ at $40{ }^{\circ} \mathrm{C}$.
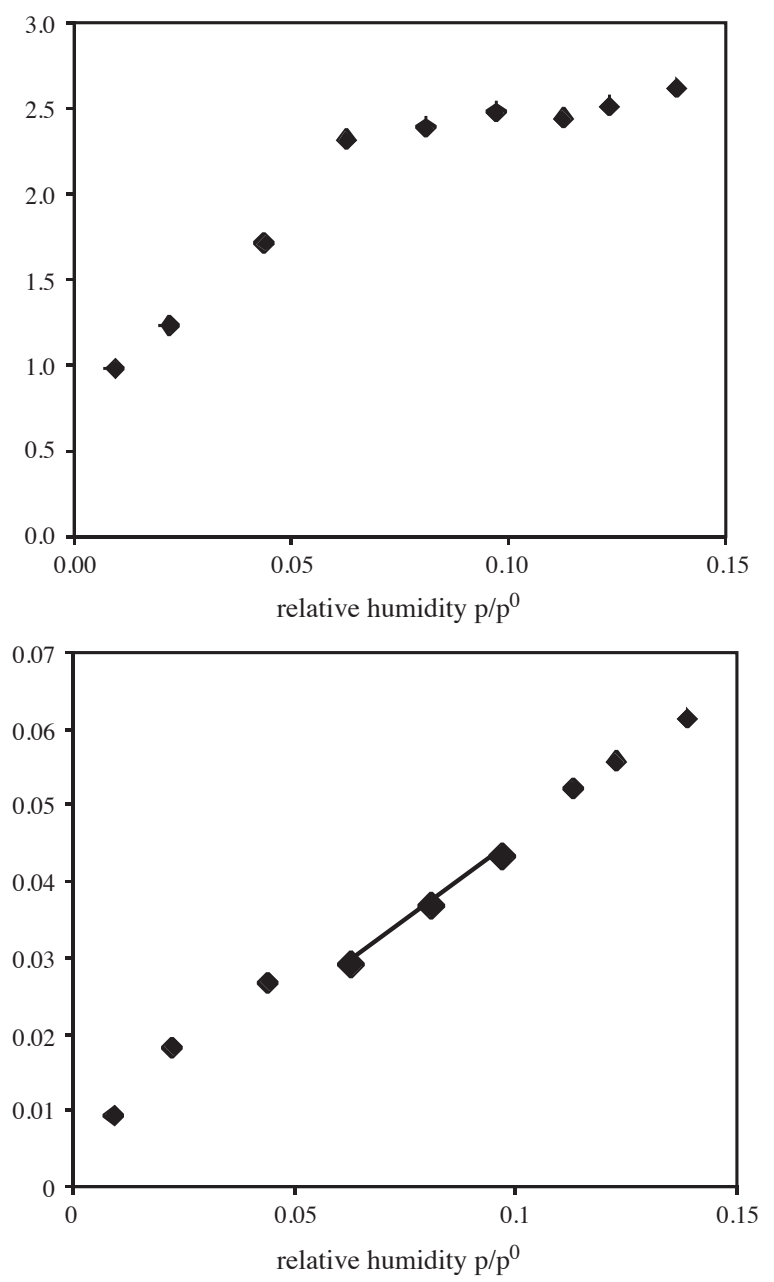

Fig. 4. Water desorption isotherm on untreated glass beads obtained by frontal analysis at $40{ }^{\circ} \mathrm{C}$ (the isotherm and the linear BET plot).

is split into two streams, one of these is kept dry and the other is saturated by passing through a gas bubbler [16]. The humidity of the carrier gas is established by the mixing ratio

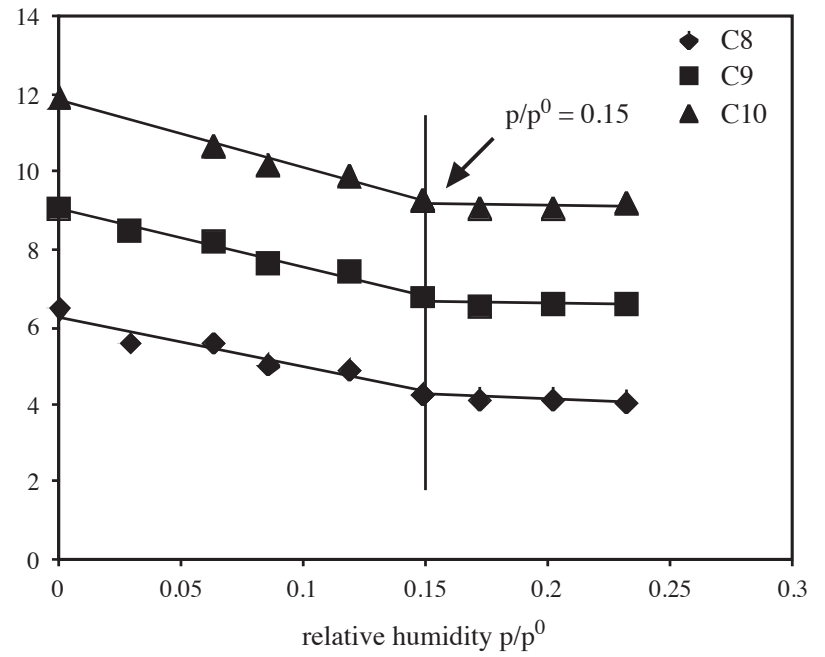

Fig. 5. Variation of free enthalpies of adsorption of apolar molecules with the relative humidity $p / p^{0}$ on untreated glass beads $4590 \mathrm{NT}$ at $40{ }^{\circ} \mathrm{C}$. 
Table 1

Variation of enthalpies and entropies of adsorption with relative humidity

\begin{tabular}{llllr}
\hline Relative humidity $p / p^{0}$ & 0 & 0.03 & 0.06 & 0.08 \\
\hline$\Delta H_{\text {ads }}(\mathrm{C} 8) \mathrm{kJ} \cdot \mathrm{mol}^{-1}$ & -27.9 & -36.0 & -43.0 & -43.9 \\
$\Delta H_{\text {ads }}(\mathrm{C} 9) \mathrm{kJ} \cdot \mathrm{mol}^{-1}$ & -30.5 & -49.6 & -47.5 & -45.6 \\
$\Delta H_{\text {ads }}(\mathrm{C} 10) \mathrm{kJ} \cdot \mathrm{mol}^{-1}$ & -37.5 & -56.7 & -49.9 & -48.9 \\
$\Delta S_{\text {ads }}(\mathrm{C} 8) \mathrm{J} . \mathrm{K}^{-1} \cdot \mathrm{mol}^{-1}$ & -67.3 & -96.3 & -130.9 & -123.9 \\
$\Delta S_{\text {ads }}(\mathrm{C} 9) \mathrm{J} . \mathrm{K}^{-1} \cdot \mathrm{mol}^{-1}$ & -67.6 & -129.1 & -130.6 & -121.2 \\
$\Delta S_{\text {ads }}(\mathrm{C} 10) \mathrm{J} . \mathrm{K}^{-1} \cdot \mathrm{mol}^{-1}$ & -80.9 & -202.4 & -131.4 & -123.8 \\
\hline
\end{tabular}

of dry to wet gases fixed by the two mass flow meters controlled by a capacitance probe. A thermostated water bath is used to avoid variations of the temperature of the bubbler and the saturated vapour pressure of water.

\subsection{The apparatus}

Fig. 2 presents the experimental apparatus combining the humidity generator and the chromatograph:

The set up presented in Fig. 2 can supply the column alternatively with a dry or a wet carrier gas. To avoid base line fluctuations due to variations of the gas flow and pressure when switching, two needle valves, valve 1 and valve 2 simulate the pressure drops of the humidity generator and of the column, respectively. In pressure and flow rate terms, the assembly comprises two totally symmetrical circuits (wet and dry). For thermodynamic equilibrium inside the bubbler, whatever the configuration of the carrier gas, a gas leak has been used which gives a constant saturated vapour pressure of water inside the bubbler.

\section{Protocol}

\subsection{Materials}

We have studied low specific surface area glass beads supplied by Sovitec. The beads have a specific surface area less than to $0.5 \mathrm{~m}^{2} / \mathrm{g}$ and a particle size distribution between $45 \mu \mathrm{m}$ to $90 \mu \mathrm{m}$. Two sets are used: first untreated and then after treatment with sulfochromic acid. The sulfochromic acid treatment consists in stirring the glass beads with the
Table 2

Variation of entropies with the relative humidity and temperature

\begin{tabular}{|c|c|c|c|c|c|c|}
\hline$p / p^{0}$ & 0 & & & 0.06 & & \\
\hline Temperature ${ }^{\circ} \mathrm{C}$ & 40 & 50 & 60 & 40 & 50 & 60 \\
\hline $\begin{array}{l}\Delta S_{\text {ads }}(\mathrm{C} 8) \\
\quad \mathrm{J} . \mathrm{K}^{-1} \cdot \mathrm{mol}^{-1}\end{array}$ & -68.4 & -67.3 & -67.9 & -132.1 & -130.9 & -131.6 \\
\hline $\begin{array}{l}\Delta S_{\text {ads }}(\mathrm{C} 9) \\
\quad \text { J.K } \\
-1 \\
. \mathrm{mol}^{-1}\end{array}$ & -68.5 & -67.6 & -68.0 & -131.7 & -130.6 & -131.2 \\
\hline $\begin{array}{l}\Delta S_{\text {ads }}(\mathrm{C} 10) \\
\quad \mathrm{J} . \mathrm{K}^{-1} \cdot \mathrm{mol}^{-1}\end{array}$ & -81.6 & -80.9 & -81.1 & -132.4 & -131.4 & -131.9 \\
\hline
\end{tabular}

acid over night, then washing abundantly with water and dried at $100{ }^{\circ} \mathrm{C}$ in an oven. The glass beads treated with sulfochromic acid will be called "4590sulfo" and the untreated glass beads "4590NT".

\subsection{Analysis conditions in IGC-ID}

The experiments are performed with a commercial GC apparatus (Hewlett Packard 6890) equipped with a highly sensitive flame ionisation detector. Helium is used as the carrier gas, columns are stainless steel tubes with an inside diameter of $4 \mathrm{~mm}$ and a length of $30 \mathrm{~cm}$, filled with about $10 \mathrm{~g}$ of glass beads. The flow rate is measured with a soap bubble flow meter and the column inlet pressure measured with a portable pressure gauge equipped with syringe needle for insertion through the injection port septum. The injector and detector are heated to $200{ }^{\circ} \mathrm{C}$. The oven temperatures are varied from 40 to $60^{\circ} \mathrm{C}$. All the columns are conditioned at $250{ }^{\circ} \mathrm{C}$ overnight to eliminate water from the surface of the glass beads. To ensure equilibrium in the bubbler, this is fed with the carrier gas at a fixed humidity ratio overnight before the analysis.

\subsection{Procedure}

Before each analysis, carrier gas at a fixed relative humidity is passed through the column for $1 \mathrm{~h}$ to ensure the thermodynamic equilibrium inside the column between the adsorption and desorption of water molecules. The retention times of different probes are then measured at the same relative humidity ratio.

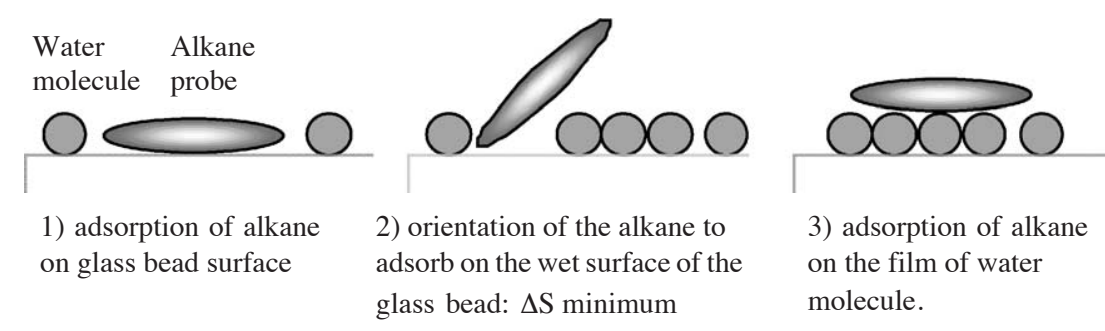

\section{Increase of the relative humidity}

Fig. 6. Schematic representation of the adsorption of alkane probes with different relative humidities. 


\section{Results}

5.1. Influence of the humidity on the adsorption of apolar molecules on untreated glass beads

\subsubsection{Specific retention volumes $\mathrm{Vg}$ and free enthalpies of adsorption $\Delta G_{\text {ads }}$}

Fig. 3 presents the evolution of specific retention volumes of three apolar probes octane (C8), nonane (C9) and decane $(\mathrm{C} 10)$ with the relative humidity $p / p^{0}$ of the carrier gas.

Fig. 3 shows that the specific retention volumes of apolar molecules on untreated glass beads vary with the relative humidity. This same observation has been reported by Boutboul et al. on starch [17] or by Sun [18] on mineral oxides. It can be seen that the specific retention volumes decrease and then reach a plateau. Stabilisation of the specific retention volumes occurs near $p / p^{0}=0.15$ whatever the probe molecules used. This can be attributed to the progressive coverage of the glass bead surface by the water molecules. The water molecules hide high energy sites from alkane probes and the retention time decreases. When the specific retention volumes become constant it may be assumed that the whole surface of the glass beads is covered with a layer of water molecules. The alkanes no longer adsorb on the glass surface but on a film of water covering the surface.

This interpretation is supported by other experiments where we determined water desorption isotherms by frontal analysis (Fig. 4). These results will be presented in another article.

The monolayer capacity, $n_{\mathrm{m}}^{\mathrm{a}}$, can be determined from the linear plot of the BET equation. It is found to be $2.4 \mu \mathrm{mol}$ of water per gram of glass beads with the relative humidity corresponding to the monolayer being $p / p^{0}=0.07$.

The water monolayer estimated by frontal analysis and application of the BET model appears at a lower relative

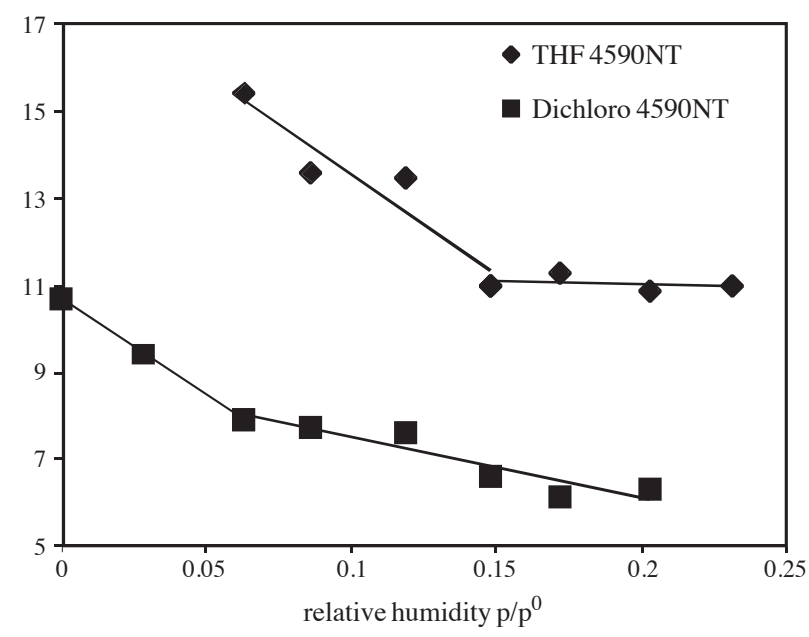

Fig. 7. Variations of specific free enthalpies of adsorption of THF and dichloroethane with the relative humidity on untreated glass beads at $40{ }^{\circ} \mathrm{C}$.

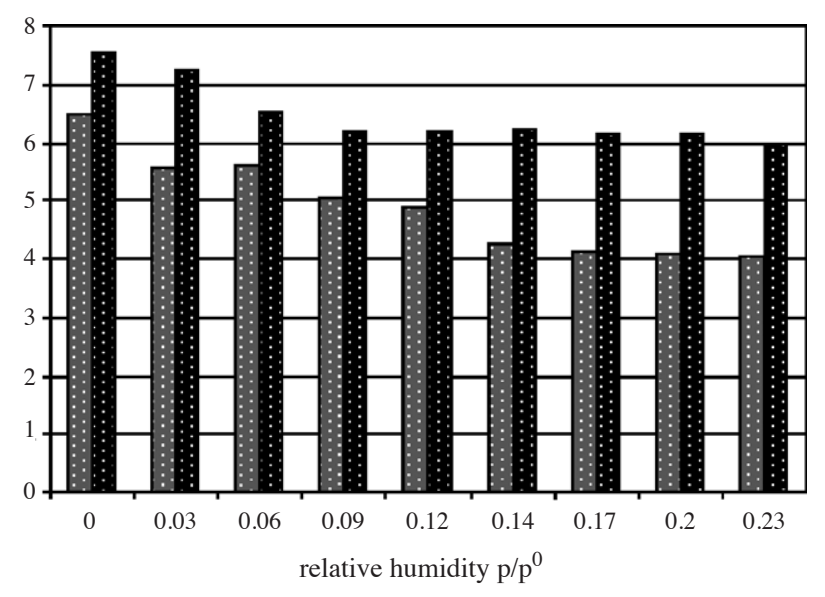

동 C8 4590NT 4590sulfo

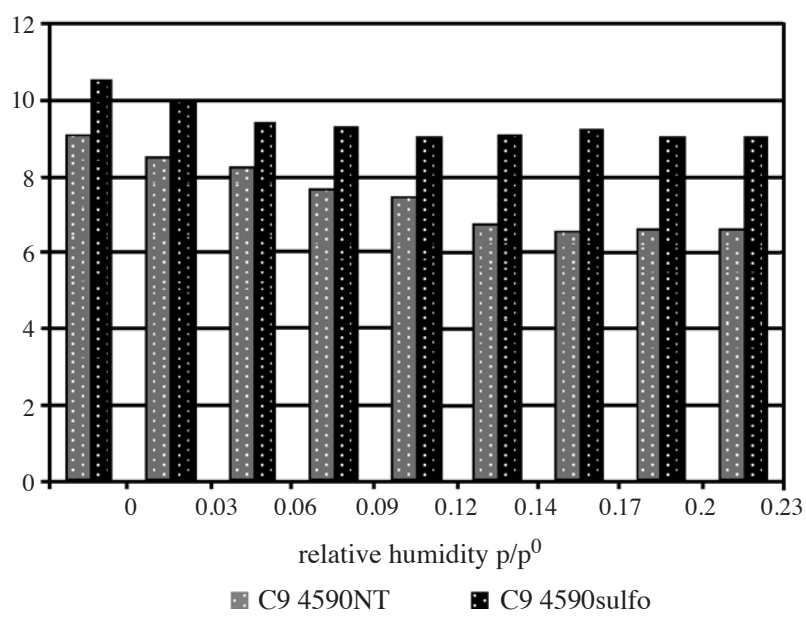

Fig. 8. Comparison of variations of free enthalpies of adsorption of octane and nonane on treated and untreated glass beads as a function of relative humidity.

humidity (0.07) than the relative humidity at which the specific retention volumes of apolar probes measured by IGC-ID become constant (0.15). The questions are therefore whether the BET model is applicable to this case and whether the hypothesis of a water monolayer on the surface glass beads is correct. We can note that the linear range is more restricted with only three points. The advantage of using IGC-ID to follow the retention volume of a probe as a function of relative humidity is that it gives a direct experimental measurement of the behaviour of the surface as a function of relative humidity. IGC-ID coupled with progressive increase of the relative humidity in the carrier gas should give good indication of the progressive coverage of the surface by water molecules.

Another way to present the influence of the humidity on adsorption properties is by studying free enthalpies of adsorption $\Delta G_{\text {ads. }}$. Fig. 5 shows the variation of $\Delta G_{\text {ads }}$ of octane, nonane and decane as a function of the humidity of the carrier gas. The same commentaries as for the variations of the specific retention volume can be made, that is to say that the stabilisation of the $\Delta G_{\text {ads }}$ seems to correspond the coverage of the surface by the water molecules. 
Table 3

Evolution of the acid base properties of untreated glass beads with the relative humidity

\begin{tabular}{llll}
\hline$p / p^{0}$ & 0.03 & 0.06 & 0.08 \\
\hline$K_{\mathrm{a}}$ & 1.63 & 1.24 & 0.89 \\
$K_{\mathrm{b}}$ & 2.54 & 1.03 & 0.26 \\
\hline
\end{tabular}

\subsubsection{Enthalpies and entropies of adsorption}

It can be seen in Table 1 that the enthalpies of adsorption of apolar molecules vary with the relative humidity.

These data show the effect of humidity on the interaction forces between glass beads and alkane probes but also gives information on the adsorption mechanism of these probe molecules. It can be seen that whatever the alkane, the entropic term goes through a minimum (at $p / p^{0}=0.06$ for C8 and C9 and at $p / p^{0}=0.03$ for C10). These minima indicate a non-random adsorption due to an orientation of the molecules at the bead surface. The existence of water molecules on the most active sites on the surface of the glass beads creates zones where the probe molecules have difficulty in gaining access. This imposes orientation of the probe molecules to reach non-wetted parts of the surface. When the relative humidity becomes high enough to approach the formation of a water film, the entropic term increases to reflect the progressive inaccessibility of the bead surface and the probe molecules gain a few degrees of liberty (Fig. 6).

If we compare the entropic variations of the three different alkanes at a given relative humidity (Table 2), the longer the chain of the alkane, the lower is the $\Delta S$. When the length of the chain increases, the alkane loses degrees of liberty to adsorb on the surface. Consequently steric hindrance of the alkane chain plays an essential role in the process of gas adsorption.

It may be noted that the entropies of adsorption $\Delta S$ of alkane molecules do not depend on the temperature but on the relative humidity. The adsorption enthalpy $\Delta H$ remains constant in the temperature range used. The variation of free energy $\Delta G$ compensates the effect of increasing of the temperature. Dutsch also described this tendency, called thermodynamic compensation, in his work on glass fibres [19].
Table 4

Values of specific surface area

\begin{tabular}{|c|c|c|c|c|}
\hline Analysis technique & Manometry & IGC fin & concentrati & \\
\hline Probe molecules & Krypton & Decane & Undecane & Dodecane \\
\hline $\begin{array}{c}\text { Specific surface area } \\
\text { of untreated glass } \\
\text { beads }\left(\mathrm{m}^{2} / \mathrm{g}\right)\end{array}$ & 0.09 & 0.09 & 0.07 & 0.09 \\
\hline $\begin{array}{l}\text { Specific surface area } \\
\text { of treated glass } \\
\text { beads }\left(\mathrm{m}^{2} / \mathrm{g}\right)\end{array}$ & 0.04 & 0.05 & 0.04 & 0.04 \\
\hline
\end{tabular}

\subsection{Influence of the humidity on the adsorption of polar molecules}

The use of polar probes allows evaluation of acid base interactions. Fig. 7 presents the variations of free enthalpies of adsorption of polar molecules and more particularly of dichloroethane and THF used respectively to study the basic and acidic character of the surface of the glass beads as a function of relative humidity.

The free enthalpies of adsorption of THF and dichloroethane vary in two stages as with the apolar molecules. In the first stage, at the low relative humidity, the $\Delta G_{\text {ads }}$ of the two probes decrease rapidly with increasing relative humidity. In the second stage the $\Delta G_{\text {ads }}$ of THF tends to a plateau whereas for the dichloroethane it continues to decrease but with a low slope without reaching a plateau. Sun et al. [19] noted this same behaviour (decrease in two stages) of $\Delta G_{\text {ads }}$ polar probes with different mineral oxides. The decrease of the $\Delta G_{\text {ads }}$ is attributed to progressive masking by the water molecules (amphoteric) of the acidic (silanols) and basic (siloxane) surface groups. The stabilisation of the $\Delta G_{\text {ads }}$ shows again the coverage of the surface of the glass beads by water molecules. However we may note that the second stage is reached more rapidly with the acid molecule (dichloroethan) than with the basic probe (THF). This result can be explained by the existence of a larger number of acidic sites than basic sites on the glass bead surfaces.

From the donor and acceptor character of electron [20] of injected probes, we can evaluate from $\Delta H_{\text {ads }}$ specific the donor (basicity) and acceptor (acidity) properties of the glass beads.
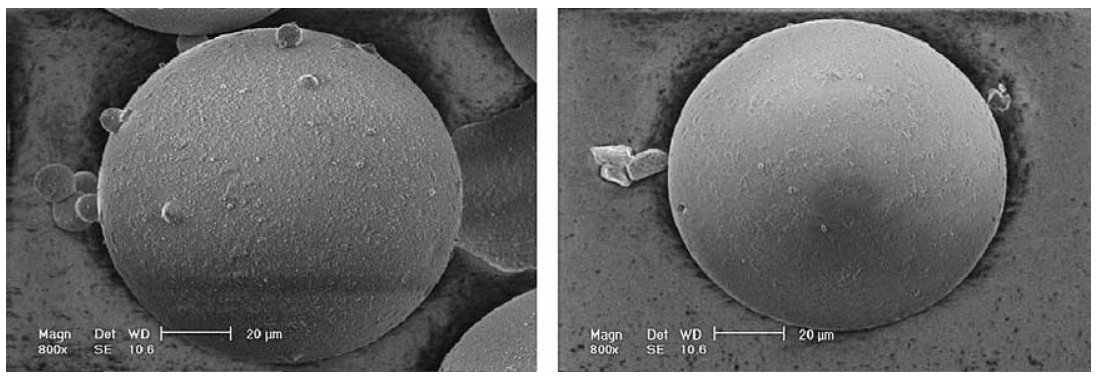

Fig. 9. MEB photos of untreated glass beads (on the left) and of glass beads treated with sulfochromic acid (on the right). 
Table 5

Variation of $\gamma_{\mathrm{d}}^{\mathrm{s}}$ of beads with the relative humidity

\begin{tabular}{llllllllll}
\hline Relative humidity $p / p^{0}$ & & 0.029 & 0.063 & 0.086 & 0.12 & 0.15 & 0.17 \\
\hline$\gamma_{\mathrm{d}}^{\mathrm{s}}\left(\mathrm{mJ} / \mathrm{m}^{2}\right) 4590 \mathrm{NT}$ & 39.63 & 39.63 & 35.29 & 36.93 & 34.99 & 35.15 & 33.10 & 34.58 & 36.38 \\
$\gamma_{\mathrm{d}}^{\mathrm{s}}\left(\mathrm{mJ} / \mathrm{m}^{2}\right) 4590$ sulfo & 47.34 & 43.08 & 43.51 & 44.26 & 43.68 & 45.84 & 45.46 & 43.90 & 50.53 \\
\hline
\end{tabular}

The acidity and basicity constants decrease when the relative humidity increases (Table 3 ). They follow the same evolution as the free enthalpy of adsorption. Cantergiani et al. [5] noted a decrease of the basic character of cottons with increasing of the relative humidity.

\subsection{Influence on the glass beads surface properties of a treatment with sulfochromic acid}

Sulfochromic acid is often used to clean glass surfaces. The interest here is to examine the limits of IGC, bearing in mind the very low specific surface of the glass beads, and establish whether the technique is sufficiently sensitive to detect variations in the surface properties of the glass beads due to this chemical treatment. Fig. 8 compares the free
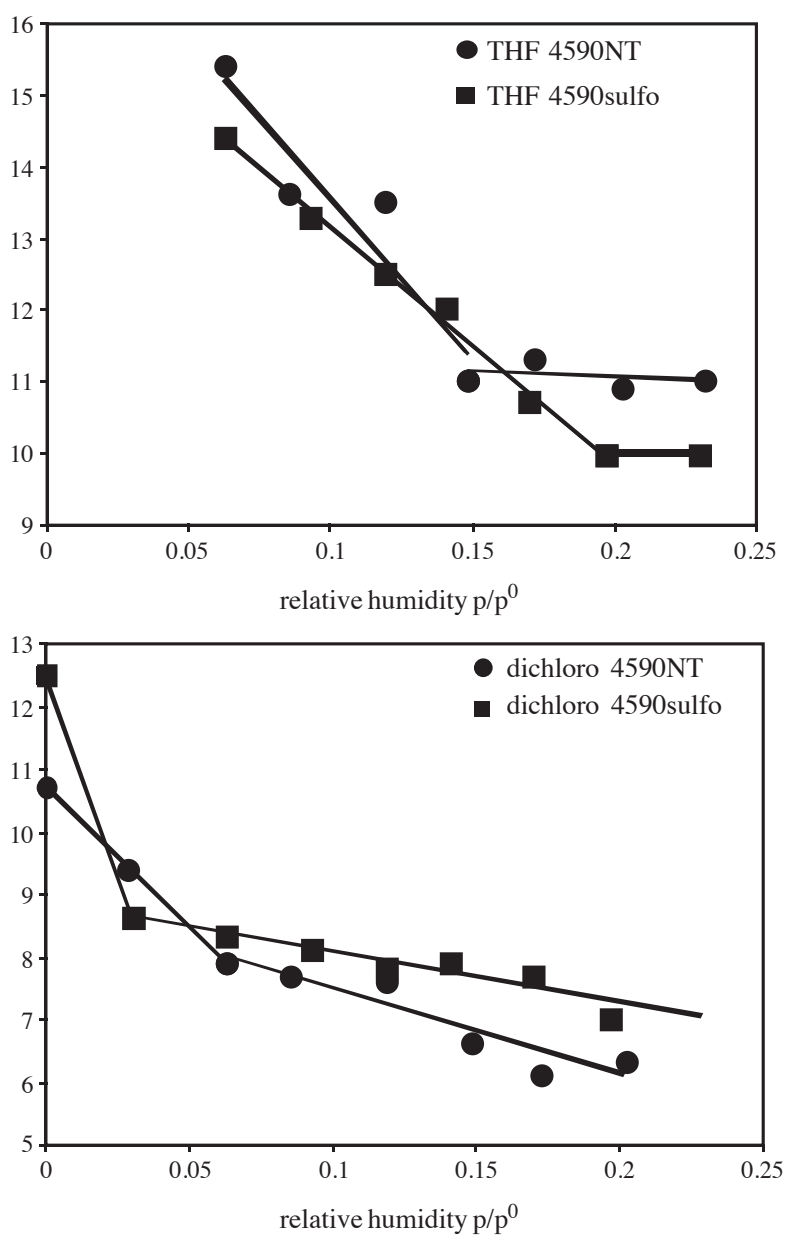

Fig. 10. Evolutions of free enthalpies of adsorption of THF and dicholoroethane on treated and untreated glass beads as a function of relative humidity. enthalpies of adsorption of octane and nonane on treated and untreated glass beads with relative humidity.

Sulfochromic acid treatment changes the potential of interaction of these glass beads and a reduction of the free enthalpy of apolar molecules is observed. One possible interpretation is the disappearance of pollutants on the surface of untreated glass beads and release of adsorption sites for the alkane probes by the sulfochromic acid treatment. The photos obtained by scanning electron microscopy (Fig. 9) show that the surface of treated beads do not have the dusty aspect observed on the untreated glass beads.

The specific surface areas obtained on one hand by manometry using krypton as probe molecule and on the other hand by inverse gas chromatography at finite concentration, prove again that treated glass beads have a less rough surface than the untreated glass beads (Table 4).

If we look at the dispersive component of the surface energy which depends on the polarizability and on the ionic potential of the surface, we can note that whatever the relative humidity, the value of the $\gamma_{\mathrm{d}}^{\mathrm{s}}$ for the treated beads is higher than $\gamma_{\mathrm{d}}^{\mathrm{s}}$ for the untreated beads (Table 5).

Sulfochromic acid may also remove alkaline ions present on the surface of the glass beads. This could explain the changes of polarizability and the ionic potential observed at the surface. Papirer has made this same observation for glass fibres subjected to different treatments [21].

Fig. 10 shows that the sulfochromic acid treatment has an influence on the acid-base surface properties. In particular the treatment can be seen to affect the acid properties of the surface as the stabilisation of the $\Delta G$ of the basic probe THF appears at a higher relative humidity $\left(p / p^{0}=0.2\right.$ instead of 0.15 before the treatment). If the sulfochromic acid releases active sites on the surface glass beads, more water is necessary to cover these sites. The sulfochromic acid treatment also seems to release basic sites as the variations of the $\Delta G$ of the dichloroethane seems to be modified after treatment.

\section{Conclusion}

We have developed a humidity generator to provide carrier gas with varying relative humidity for gas chromatography. This has been used in inverse gas chromatography to study the surface properties of glass beads with very low specific surface $\left(1 \mathrm{~m}^{2} / \mathrm{g}\right)$. ICG-ID coupled to a progressive coverage of the glass beads surface with water molecules allows the determination of the value of relative humidity at which the surface properties become constant. This value of 
relative humidity is higher than the relative humidity corresponding to the formation of the water monolayer according to the BET model. We also show the effect of a sulfochromic acid treatment on the surface of the glass bead, in that it seems to release acid sites or to make surface ions migrate and increase the polarizability of the surface.

\section{References}

[1] B.C. Hancock, C.R. Dalton, The effect of temperature on water vapor sorption by some amorphous pharmaceutical sugars, Pharmaceutical Development and Technology 4 (1999) 125-131.

[2] H.E. Newell, G. Buckton, D.A. Butler, F. Thielmann, D.R. Williams, The use of inverse phase gas chromatography to study the change of surface energy of amorphous lactose as a function of relative humidity and the processes of collapse and crystallisation, International Journal of Pharmaceutics 217 (2001) 45-56.

[3] K.A. Riganakos, P.G. Demertzis, M.G. Kontominas, Water sorption by wheat and soy flour: comparison of three methods, Journal of Cereal Science 20 (1994) 101-106.

[4] A. Boutboul, P. Giampaoli, A. Feigenbaum, V. Ducruet, Use of inverse gas chromatography with humidity control of the carrier gas to characterise aroma-starch interactions, Food Chemistry 71 (2000) $387-392$.

[5] E. Cantergiani, D. Benczedi, D.R. Williams, Use of inverse gas chromatography to characterize cotton fabrics and their interactions with fragrance molecules at controlled relative humidity, Journal of Chromatography 969 (2002) 103-110.

[6] H. Balard, A. Saada, B. Siffert, E. Papirer, Influence of water on the retention of organic probes on clays studied by IGC, Clays and Clay Minerals 45 (1997) 489-495.

[7] C.J. van Oss, R.F. Giese, Z. Li, K. Murphy, J. Norris, M.K. Chaudhury, R.J. Good, Determination of contact angles and pore sizes of porous media by column and thin layer wicking, Journal of Adhesion Science and Technology 6 (1992) 413-428.

[8] J.R. Conder, C.L. Young, Physicochemical Measurement by Gas Chromatography, Wiley, New York, 1979.
[9] I. Tijburg, J. Jagiello, A. Vidal, E. Papirer, Inverse gas chromatographic studies on silica: infinite dilution and finite concentration measurements, Langmuir 7 (1991) 2243-2247.

[10] J.B. Donnet, E. Custodéro, T.K. Wang, G. Hennebert, Energy site distribution of carbon black surfaces by inverse gas chromatography at finite concentration conditions, Carbon 40 (2002) 163-167.

[11] H. Hadjar, H. Balard, E. Papirer, An inverse gas chromatography study of crystalline and amorphous silicas, Colloids and Surfaces. A, Physicochemical and Engineering Aspects 99 (1995) 45-51.

[12] A. Voelkel, A. Krysztafkiewicz, Acid base properties of silicas modified by organic compounds as determined by inverse gas chromatography, Powder Technology 95 (1998) 103-108.

[13] H. Balard, M. Sidqi, E. Papirer, J.B. Donnet, A. Tuel, H. Hommel, A.P. Legrand, Study of modified silicas by inverse gas chromatography: Part I. Influence of chain length on grafting ratio, Chromatographia 25 (1988) 707-711.

[14] H. Balard, M. Sidqi, E. Papirer, J.B. Donnet, A. Tuel, H. Hommel, A.P. Legrand, Study of modified silicas by inverse gas chromatography: Part II. Influence of chain length on surface properties of silicas grafted with $\alpha-\omega$ diols, Chromatographia 25 (1988) 712-716.

[15] F.M. Fowkes, Industrial Engineering Chemistry 56 (1964) 40.

[16] M. Heinonem, A humidity generator with a test chamber system, Measurement 25 (1999) 307-313.

[17] A. Boutboul, P. Giampaoli, A. Feigenbaum, V. Ducruet, Influence of the nature and treatment on starch on aroma retention, Carbohydrate Polymers 47 (2002) 73-82.

[18] C. Sun, J.C. Berg, Effect of moisture on the surface free energy and acid base properties of mineral oxides, Journal of Chromatography A 969 (2002) 59-72.

[19] V. Dutschk, E. Mader, V. Rudoy, Determination of polarity parameters for glass fibres by inverse gas chromatography: some results and remarks, Journal of Adhesion Science and Technology 15 (2001) $1373-1389$.

[20] Gutmann, The Donor-Acceptor Approach To Molecular Interactions, Plenum Press, New York, 1978.

[21] E. Papirer, Characterization of fibers and fillers for composite materials using inverse gas chromatography, Proceedings of the First International Conference on Composite Interfaces, 1986, pp. 203-213. 